\title{
A Survey on the Revamped Future of Transport
}

\author{
Heena Tamboli ${ }^{1,}{ }^{*} J y o t i$ Malhotra ${ }^{1}$, SambhajiSarode ${ }^{1}$ and Shruti Deshpande ${ }^{1}$ \\ ${ }^{1}$ CSE, School of Engineering, MIT ADT University, Pune (MS), ,India.
}

\begin{abstract}
Transport, a movement activity from home to work, studyor market place is one of the basic needs like food, shelter clothes. Nowadays, sharing and adaptive transport services are in demand due to increased traffic and rush to public transport; contributing to saving fuel, fuel cost, and above all time. Transport sharing consists of car sharing, auto-sharing and also bike sharing. . Where in, two or more individuals targeting the same location opts to share transport system. The transport sharing model, especially taxi services also adds various adaptive facilities a one-way and two-way station-based sharing system. These services help individuals to reserve their onlineseats with bus and car-sharing. This paper reviews various existing shared and effective ways of transportation. The observations include different route matching and applied machine learning techniques used by the models which are placed in working using Google maps, APIs, sensors, and Smartphone applications to get and track thedestination.In addition, the manuscript also presents the assessment taken on the communal sphere to acquire various transport facilities adopted by people and the different challenges faced by them.
\end{abstract}

\section{Introduction}

There are 466 million working people in India and in the survey [1]it is found that 23 million and roughly 70 million people use public transport services like train and bus; moreover, individuals also prefer to either hire an auto, cab or travel by their private bike or car. Among the working category, some people are profiled with fulltime jobs and some are associated with part-time jobs. People face many travel issues especially with public transports, leading to traffic congestion and sudden change in the scheduled time. Onthe other hand, few individuals don't preferthe hassles of owning a car like its maintenance, fuel, insurance, parking, and health issues. Such category-A individuals rely on publictransportservices like-bus, trains, auto,and cabs.

Category-B peopleprefer to take the journey on their private transport models with cars or bikes; taking up too much space on the roads. Considering these pros and cons of public and private transport models, traveling and traffic challenges are mostly faced in urban areas. To be specific, we have taken an example of Hinjewadi located in the Pune city - one of the largest cities in the Indian state of Maharashtra. Hinjewadi is well known IT hub for local professionals. Above 2.5 Lacs IT professionals travel daily to and from IT Park. Hinjewadi area is continuously facing serious traffic problems especially during rush hours where trafficisatitshighest.
Road traffic emissions produce greenhouse gases that contribute to global warming, causing serious pollution problems. Every Person riding in a private car increases the number of cars, stemming from escalating traffic and pollution. Individuals of Category-B can also willingly contribute in straight forward and convenient shared public transport services such as car or bike pool reducing the street space, fuel costs, and traffic congestion. The main purpose is to minimize congestion on the street by reducing vehicle flow by joining passengers of the same landing space.

Well-known taxi services namely Ola and Uber [2] are huge alternatives to public transportation filling a hole in our transportation ecosystem. Whereby, individuals can easily book the taxi by looking down into their apps and can easily track their ride with their relatives for security purpose. The major downsides of these services are- the expensive rates, ride cancellation, crimes, sexual assault, etc. Hence, shared transport is the most suitable solution for all. As sketched in figure 1, Car/bus/bike/auto are the different available transport sharing systems and it saves money, reduces traffic congestion, increases fuel efficiency, saves time, and above allincreasesmobility.

\footnotetext{
*Corresponding author: heenatamboli1991@gmail.com
} 


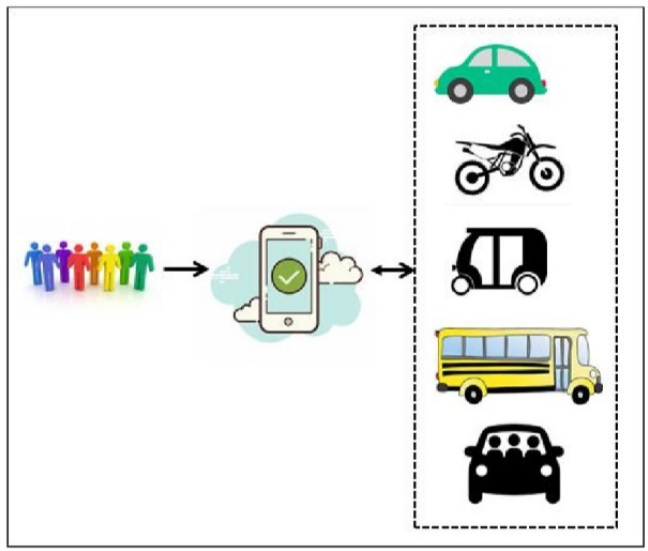

Fig. 1.Different ways of Shared Transport.

In this paper, we present the study of existing shared transport systems along with their upsides, downsides and the same is illustrated in section II followed by our observations covered in section III. At the end, conclusion and references are framed in section IV and $\mathrm{V}$. We also indicate some comparative and algorithmic features with theexistingsolutions.

\section{Literature review}

This section reveals different solutions adopted by various authors on transportation systems. We place the transport reviewintotwo segments:

2.1. Questionnaire-based assessment of various public and private transport options preferred by individuals.

\subsection{Existing solutions for economic transport.}

\subsection{Questionnaire-based assessment}

A survey was taken by framing the following questions to understand various travel options grabbed by the individuals and challenges faced during the journey.

1. Their workplace location and how do they travel to their workplace?

2. What challenges do they face during travel?

3. Any suggestions to improvise the existing scenario?

4.Any preventive measures on working women's safety during transport?

The observations drawn from various responses helped us to understand existing options and the challenges. It was observed that nearly $41.6 \%$ ofindividuals reside inPune and among them, nearly $33.7 \%$ of people travel by public transport bus. The average percentage of individuals traveling by personal two-wheelers and fourwheelers are $32.6 \%$ and $12 \%$. Moreover, only $6 \%$ of them prefer carpooling as shown in figure 2 . Thus, we conclude that individuals should voluntarily contribute more to carpooling for social and economic benefit.

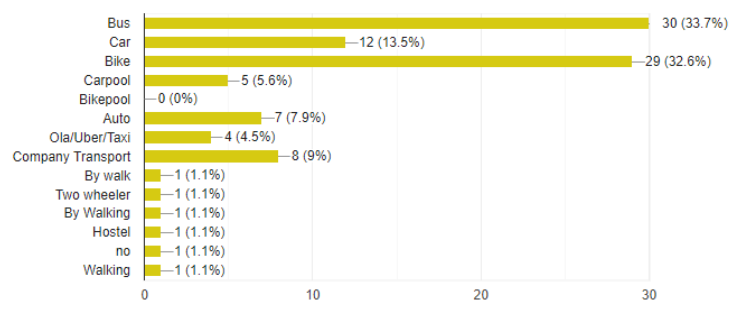

Fig 2: Work-place travel distribution

As shown in figure 3, out of various listed challenges including traffic, parking, time, road maintenance, unavailability of taxis and buses; it was also observed that nearly $76.4 \%$ individuals recorded traffic as one of the major challenges during their travel followed by time and parking contributing as $32 \%$ and $19 \%$. Thus, we address that individuals should consider these components of parking problems, air pollution, traffic congestion, health complications, together with fuel and vehicle maintenance crisis and go for green ride i.e. shared public or private transport.

In addition to this, we also received some suggestions to overcome these challenges such as- Stringent rules for traffic, increase the police protection on roads for traffic regulations, date-wise parking, and many more. Majorly individuals focused on - use more public transport than private transport and car-pooling.

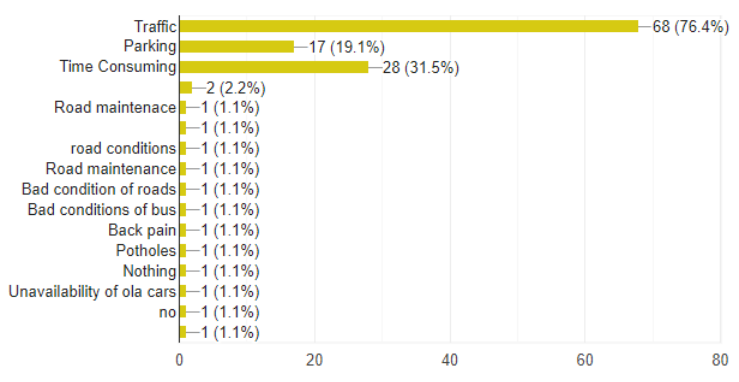

Fig3: Challenges faced during the travel

\subsection{Existing solution for economic transport}

This sub-section reveals the related study of diverse existing public and private transport systems along with their parameters, advantages, and disadvantages.

With respect to public transport such as bus, Palak Patel et. al. [3] addresses traffic congestion on roads and its reduction through an intelligent public transport system using the Internet of Things. The author highlights various application areas including - traveler's information, improved public transportation, and traffic management along with emergency solutions for an ambulance or higher priority vehicles. The research focuses mainly on sensor-based automation for - 
Electronic fare collection, GPS based highway data collection to control traffic, vehicle data collection improving transport and tracking efficiency. Authors plotted the importance of IoT based sensor intelligence for public transport benefitting traffic management, seat occupancy, and security.

The author Kaijun Liu et. al. [4] has stated the importance of bus sharing over the car-sharing system. Car sharing has a drawback of low capacity and high cost. Whereas the bus shared service is comparatively economical. The paper optimizes the ride-matching service for its success rate with the help of a Contraction-Based algorithm scanning the count of visited and unvisited people. Divide and Conquer method is used for energy-efficient location-allocation in the system. It also provides decision support for government authorities for urban bus management and its planning. This is an effective approach for solving the taxi-hailing difficulty in urban areas.

The author Xiangjie Kong, Tao Tang et. al. [5] has proposed bus route planning. It is useful for reducing traffic congestions. The authors have focused on planning dynamic routes. It also includes the prediction of travel requirements. Bus Selection algorithm, along with station selection algorithms are defined for bus selection. This approach is used for shared subway shuttle bus services consisting of mobile data. Origin and Route location parameters of individuals are recorded for getting optimal and effective routes.

The authors of [6] have proposed another pool system based on bike-sharing. For the people traveling by public transports like buses and trains; the author suggested providing bicycle parking stands near public transit stations. This solution can help people to reach their workplaces within or before time. The only issue raised for this solution was unnecessary stands for unused bikes. This can be addressed by opting Steady State method, recording information such as bike allocation, it's return time and demand rates. Electric bicycles are more expensive but can be used for long distances. Bikeshare pool must be provided near the customer's home and workplace.

In this paper, the author Nicola Sacco[7] has proposed a one-way car-sharing system. The system is effective for users that may leave the vehicle anywhere in the network or at any station. The vehicle relocation task is challenging here. The system must decide when and how to distribute the vehicle. Heuristic Strategy used to minimize the waiting times of pending requests. In Userbased relocation methodology, customers can drop a vehicle off in exchange for a fair discount. The userbased relocation allows increasing the profit of the sharing system.

In this paper, [8] the authors have proposed the reservation scheme to manage rental reservations of the car-sharing system. In an auction scheme, drivers bet for rental start time contributing to reduced rental fare. For combinatorial auctions, Vickrey-Clarke-Groves (VCG) mechanism is used. This mechanism guarantees a fair assignment for the drivers. This is for two-way stationbased car-sharing systems. The potential benefits are higher in the system with shorter rentals from drivers.

With respect to carpooling author Fu-Shiung Hsieh et. al. [9] mentioned that carpooling is a collective transportation model based on shared use of private cars. Carpooling reduces the number of cars as it groups people targeting the same destination or multiple destinations in the journey. It helps in reducing pollution, users traveling cost and time. The author also discussed on daily carpooling and Long-term carpooling. In carpooling two or more passengers traveling together in the same direction so they get benefited from sharing the driving costs, parking fees, and economic advantages. This research uses Android applications in Java languages. The android platform makes it easy and handy to use sensors on the device. It uses sensors and Google Maps to determine locations and motion capabilities. Another car-pooling solution based on route-matching and machine learning is elaborated in the article published by authors of [10].

Table 1. Parametric summary of prior research

\begin{tabular}{|c|c|c|c|c|}
\hline Approach & $\begin{array}{l}\text { Travel } \\
\text { Cost }\end{array}$ & $\begin{array}{l}\text { Passengr } \\
\text { seating } \\
\text { Capacity }\end{array}$ & $\begin{array}{l}\text { Travel } \\
\text { Time }\end{array}$ & $\begin{array}{l}\text { Algorith } \\
\text { mic } \\
\text { strategy }\end{array}$ \\
\hline $\begin{array}{l}\text { Bus } \\
\text { Pooling } \\
{[4]}\end{array}$ & Least & $\begin{array}{l}\text { Range of } \\
10-50 \\
\text { passenges }\end{array}$ & More & $\begin{array}{l}\text { Divide } \\
\text { and } \\
\text { Conquer } \\
\text { method }\end{array}$ \\
\hline $\begin{array}{l}\text { Bus } \\
\text { shuttle } \\
\text { service[5] }\end{array}$ & Least & $\begin{array}{l}\text { Range of } \\
10-20 \\
\text { passenges }\end{array}$ & More & $\begin{array}{l}\text { Bus and } \\
\text { Station } \\
\text { Selection } \\
\text { algorithm }\end{array}$ \\
\hline $\begin{array}{l}\text { Bike } \\
\text { sharing[6] }\end{array}$ & $\begin{array}{l}\text { Averag } \\
\mathrm{e}\end{array}$ & $\begin{array}{l}\text { Two } \\
\text { passenges }\end{array}$ & $\begin{array}{l}\text { Relatively } \\
\text { Less }\end{array}$ & $\begin{array}{l}\text { Steady } \\
\text { State } \\
\text { method }\end{array}$ \\
\hline $\begin{array}{l}\text { One-way } \\
\text { carsharing } \\
{[7]}\end{array}$ & High & $\begin{array}{l}\text { Range of } \\
4-8 \\
\text { passenger } \\
\text { s }\end{array}$ & Less & $\begin{array}{l}\text { Relocatio } \\
\mathrm{n} \\
\text { algorithm }\end{array}$ \\
\hline $\begin{array}{l}\text { Carpoolin } \\
\mathrm{g}[8]\end{array}$ & $\begin{array}{l}\text { Averag } \\
\text { e or } \\
\text { high }\end{array}$ & $\begin{array}{l}\text { Range of } \\
4-8 \\
\text { passenger } \\
\text { S }\end{array}$ & Less & $\begin{array}{l}\text { First come } \\
\text { first serve }\end{array}$ \\
\hline $\begin{array}{l}\text { Carpoolin } \\
\mathrm{g}[9]\end{array}$ & $\begin{array}{l}\text { Averag } \\
\text { e or } \\
\text { high }\end{array}$ & $\begin{array}{l}\text { Range of } \\
4-8 \\
\text { passenger } \\
\text { s }\end{array}$ & Less & $\begin{array}{l}\text { Matching } \\
\text { Algorithm }\end{array}$ \\
\hline $\begin{array}{l}\text { Carpoolin } \\
\mathrm{g}[10\end{array}$ & $\begin{array}{l}\text { Averag } \\
\text { e or } \\
\text { high }\end{array}$ & $\begin{array}{l}\text { Range of } \\
4-8 \\
\text { passenger }\end{array}$ & Less & $\begin{array}{l}\text { K-means } \\
\text { algorithm }\end{array}$ \\
\hline $\begin{array}{l}\text { Bike- } \\
\text { sharing } \\
{[11]}\end{array}$ & $\begin{array}{l}\text { Averag } \\
\mathrm{e}\end{array}$ & $\begin{array}{l}\text { Two } \\
\text { passenger } \\
\text { s }\end{array}$ & $\begin{array}{l}\text { Relatively } \\
\text { less }\end{array}$ & $\begin{array}{l}\text { Greedy } \\
\text { algorithm }\end{array}$ \\
\hline
\end{tabular}


In yet another research the author Rahman, M. S., \& Kiyomoto, S.[11] mentioned the importance of more economical Bike Sharing Systems (BSS); as it is one of the major components of intelligent transport systems in smart cities. To ensure a user-focused and robust service, Bike Sharing System should be a part of a multi-modal journey environment such that a user can plan her/his whole journey conveniently. Bike Sharing Systems should offer services to both bike users and Bike Sharing Service Operators. It proposes a secure bike-sharing system.

Authors of [11] have also proposed dual-stage algorithms. The first algorithm allows a user to reserve a bike and parking space according to her/his journey plan through her multimodal journey planning application. In the second algorithm, it shows how bike distribution management can be done in a secure way so that the system can distribute bikes to various stations according to the real-time demand. It provides a secure bike sharing system using encrypt decrypt methods. User authentication controls are designed to verify identity to process ticketing, reserving, parking services. They use Sensor-integrated smart bikes, and Smartphone apps and Google Maps for tracking locations. The review of prior research is summarized in table 1 along with the features including travel cost, passenger seating capacity, travel time and algorithmic strategies.

In this paper ,[15] the authors have propoesd public bike sharing system. In that bikes were provided for public use. User can find and take bike, ride it for his destination and leave for the next one. It provide the real-time bike rental information to the public and records the information of how bikes move each day inside the system. This infirmation is collected and used for reference to understand patterns of bike flow. They conduct statistical analysis or data mining to understand pattern of demands.

\section{Observations}

Post review, we believe and propose that an efficient transport pooling system can be designed using locationbased APIs and/or ZigBee based wireless as mentioned in [12],[13],[14] infrastructure for better location detection, tracking, and communication. Hence, the importance of pooling can contribute to a convenient and secure ecosystem.

The Pooling system shall be equipped with online API services and offline intranet facility services to handle extreme cases. However, the Pooling system shall not necessary to be dependent on online API services considering the network connectivity issues in an emergency service. Having both the facility at the place is always better to handle real-time scenarios. It is essential especially for urban regions at great extent compared with rural regions. Presently, Urban regions are badly suffering from pollution, traffic jams, accidents, and safety. To overcome these issues, we need to design a system to manage the transport problem with the highest level of safety at an affordable rate to everyone. Presently every person has a mobile device, so utilizing it for location identification becomes easy and will not demand any additional hardware requirement. Women's safety is an important concern when we develop a pooling system.

\section{Conclusion}

In this paper, we have reviewed various transport sharing systems including car, bus, and bike-sharing. It allows the rider to customize the route and pick up and drop to the desired location. This study helped us to understand the process of matching the rides and sharing the transport for the same destination(s) using different clustering algorithms like K-means algorithm, greedy algorithm, relocation and matching algorithm we determine the transport sharing system. We summarize that implementation of car-sharing or pooling can be energy-efficient, traffic reducing, time-efficient and economic benefits leading to stress-free society and green ride.

\section{References}

https:/www.indiaspend.com/only-4-75-millionjoin-indias-workforce-annually-not-12-million-asclaimed-70548/

https://www.olacabs.com/; https://www.uber.com/

Patel, P., Narmawala, Z., \& Thakkar, In Emer. Res. in Computing, Info., Comm. and App., 231,(2019)

Liu, K., Zhang, J., \& Yang, Q., IEEE Access, 7, 74248, (2019).

Kong, X., Li, M., Tang, T., Tian, K., MoreiraMatias, L., \& Xia, F. IEEE Trans. on Auto. Sci. and Engg., 15, 1507, (2018).

Tang, G., Keshav, S., Golab, L., \& Wu, K., IEEE Transactions on Intelligent Transportation Systems, 19, 2279, (2018).

Di Febbraro, A., Sacco, N., \& Saeednia, M., IEEE Transactions on Intelligent Transportation Systems, 20, 628, (2018).

Roca-Riu, M., \& Menendez, M., IEEE Access, 7, 154627, (2019).

Hsieh, F. S., IEEE 31st International Conference on Advanced Information Networking and Applications, 972, (2017)

Samy, M., \& Elkorany, A. M. IEEE/ACM International Conference on Advances in Social Networks Analysis and Mining, 702, (2018).

Rahman, M. S., \& Kiyomoto, S., IEEE International Conferences on Big Data and Cloud Computing (BDCloud), Social Computing and Networking (SocialCom), Sustainable Computing and 
Communications (SustainCom)(BDCloudSocialCom-SustainCom), 437,(2016).

Sambhaji, S., \& Bakal, J., Journal of Telecommunication, Electronic and Computer Engineering, 10, 65, (2018).

Sambhaji, S., \& Bakal, J., Journal of Telecommunication, Electronic and Computer Engineering, 9, 37, (2017).

Sambhaji, S., \& Bakal, J., Proceedings of the International Congress on Information and Communication Technology, 535, (2016).

Wang, I. L., \& Wang, C. Second IIAI International Conference on Advanced Applied Informatics, 306, (2013). 